\title{
EDUCAÇÃO E DIREITOS DA CRIANÇA EM SITUAÇÃO DE RISCO E PERIGO SOCIAL: UMA ANÁLISE DOS MARCOS LEGAIS PARA A PRIMEIRA INFÂNCIA, NO BRASIL E EM PORTUGAL ${ }^{*}$
}

Ana Katia Alves dos Santos

Fernando Ilídio Ferreira

"Professor J: Acredito que os caminhos a serem traçados para a efetivação dos direitos infantis devem partir do respeito que devemos ter com as crianças, o olhar sensível às suas necessidades e a valorização como sujeitos" (SANTOS, 2017, p.230).

\section{Introdução}

Este capítulo aborda a questão dos direitos da criança em situação de risco e perigo social, com enfoque no direito a uma Educação Básica de qualidade. Para tal, são analisados os marcos legais da primeira infância, no Brasil e em Portugal. Há décadas a qualidade na Educação Básica é um dos fundamentos mais defendidos, atendendo às suas implicações no desenvolvimento humano, social e econômico, assim como na promoção e na garantia dos direitos humanos das crianças. Uma Educação Básica edificada no foco da qualidade, que deve se prolongar ao longo da vida, não pode deixar de fora as crianças de zero a seis anos de idade, faixa etária mundialmente definida como Primeira Infância. Esse foco aponta o horizonte para o qual as políticas e os investimentos deveriam se voltar, de modo a garantir base sólida para uma futura geração de jovens e adultos saudáveis, com perspectivas de formação e desenvolvimento biológico, psicológico, intelectual e atuação competente na sociedade.

A busca por ampliação de qualidade na educação de crianças se fortalece e amplia após atualizadas defesa e sistematização de instru-

${ }^{*}$ DOI - 10.29388/978-65-86678-02-4-0-f.269-294 
mentos legais que concebem a criança como sujeito de direitos. Nesse processo sócio-histórico e político de conquista de direitos, a promulgação do Estatuto da Criança e do Adolescente (ECA), em 1990, no Brasil, substituindo os antigos códigos Mello Mattos de 1927 e Códigos de Menores de 1979, representa um marco histórico, ao qual se juntou, em 2016, o seu 'complemento' intitulado Marco Legal da Primeira Infância. Esses instrumentos se tornaram um novo paradigma fundamental para a elaboração de novas políticas públicas e práticas sociais relacionadas à vida infantil. Portugal foi pioneiro, no período da Primeira República ${ }^{1}$, ao aprovar a Lei de Proteção à Infância, no ano de 1911 (PORTUGAL, 1911), revelando uma concepção de criança como sujeito de direitos. Essa Lei distinguiu a criança do adulto e o Direito Penal do Direito de Menores, ou seja, o modelo de Proteção relativamente ao modelo de Justiça. (CANDEIAS e HENRIQUE, 2012).

Neste sentido, ambas as nações vêm revelando ampliação do compromisso no que tange à Educação, incluindo a Meta 4 da agenda 2030, das Organizações das Nações Unidas para o Desenvolvimento Sustentável, que tem Brasil e Portugal como signatários. O compromisso com essa Meta, que se insere no âmbito mais geral dos Objetivos de Desenvolvimento Sustentável (ODS), visa assegurar educação inclusiva e equitativa de qualidade, promovendo aprendizagens ao longo da vida para todos/as. Cenário inconteste que destaca as crianças de menor idade e o seu acesso universal à educação básica, ampli ando, assim, as oportunidades daquelas que são mais vulneráveis e se encontram até em situações de risco de perigo. As crianças pequenas são seres produtores de cultura e se constroem em relação de alteridade com os adultos (professores, pais, profissionais da educação, governantes, e/ou outros responsáveis legais), que devem defender, sistematizar e contribuir para a garantia dos seus direitos, sendo um compro-

\footnotetext{
${ }^{1}$ Em Portugal, a implantação da Primeira República ocorreu em 1910. Consistiu no sistema político vigente em Portugal após a queda da Monarquia Portuguesa, entre a revolução republicana de 5 de outubro de 1910 e o golpe de 28 de maio de 1926, que deu origem à Ditadura Militar, mais tarde Ditadura Nacional e posteriormente Estado Novo.
} 
misso uma manifestação necessária no contexto das práticas sociais e educativas para este século.

Metodologicamente, o estudo aqui apresentado não se inscreve, stricto sensu, no âmbito da Educação Comparada, pois o sentido da comparação não tem a ver apenas com a utilização de um método de pesquisa, buscando submeter os dados a categorias exaustivas e mutuamente exclusivas, mas essencialmente com a adoção do método comparativo como recurso de análise de marcos legais relevantes dos dois países. Este tipo de análise tem como principal objetivo captar regularidades e singularidades; cotejar aspetos convergentes e dissonantes; identificar conjunturas, lutas e tendências, entre outros aspetos emergentes do material empírico, não ignorando a enorme influência que vêm exercendo, nas últimas décadas, diversas organizações e agências supranacionais, como a União Europeia, a OCDE, o Banco Mundial e outras que, munindo-se de poderosos instrumentos de medição e comparação, têm na mira a estandardização de políticas. Neste sentido, o método comparativo é propício à apreensão da dimensão internacional das políticas e dos processos educativos, ainda que no presente estudo o escrutínio abranja apenas dois países.

Este estudo volta-se fundamentalmente às crianças em situação de risco ou perigo social ${ }^{2}$, tendo em vista a garantia e a manutenção dos seus direitos para melhor participação na vida social, em sua vida presente e futura. Pretende-se pesquisar e refletir em torno da seguinte questão: Quais os instrumentos legais que sustentam as práticas sociais e educativas voltadas para a Primeira Infância, em especial aquelas que se encontram em situação de risco ou vulnerabilidade só-

\footnotetext{
${ }^{2}$ Criança em risco é aqui considerada aquela que tem os seus direitos fundamentais violados, a exemplo, o Direito à vida, o Direito à Convivência Familiar e Comunitária, à Educação e à Saúde, o Direito ao Esporte e Lazer, o Direito à Liberdade, Dignidade e Respeito e o Direito à Preparação e Proteção ao Trabalho. A violação destes direitos expõe as crianças a situações de vulnerabilidade social e potencial perigo, como a exposição à extrema pobreza, a inserção na marginalidade, a violência física e psicológica, a exploração de várias ordens (moral e física), ao uso de entorpecentes e envolvimento com a criminalidade e a baixa expectativa de vida digna e 'produtiva' no futuro.
} 
cial, em Portugal e no Brasil? Esses marcos legais contribuíram para a construção da noção de criança como sujeito de direitos? Com enfoque nos documentos legais voltados aos direitos da criança na Primeira Infância, em Portugal e no Brasil, procuraremos ressaltar cinco categorias básicas, que aparecerão citadas e comentadas ao longo do texto (Figura 1).

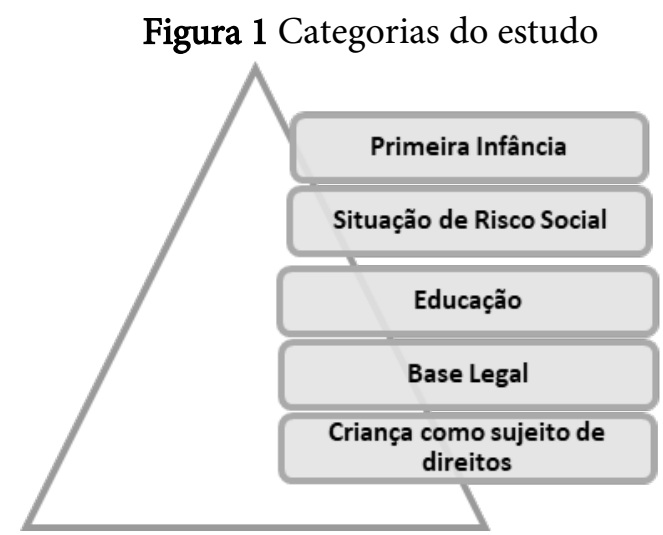

Fonte: criação própria

Tais categorias articuladas compõem o quadro geral necessário à construção e ao desenvolvimento da análise proposta.

\section{A questão dos direitos e das políticas de educação da primeira infância}

A discussão em torno dos direitos e das políticas públicas de educação da primeira infância tem sido menos intensa em relação à faixa etária dos 0 aos 3 anos, correspondente à comumente designada Creche, do que em relação à faixa etária dos 4-5 anos, para a qual existem as escolas infantis/jardins de infância, denominações usadas no Brasil e em Portugal, respetivamente.

Como já mencionado, em 1911, Portugal coloca-se na vanguarda da proteção da criança ${ }^{3}$ ao assumir uma nova perspectiva a res-

\footnotetext{
${ }^{3}$ A proteção de menores em Portugal assume uma grande importância com a publicação do Decreto de 1 de janeiro de 1911, que criou as Comissões de Proteção, e, sobretudo, com a publicação da Lei de Proteção à Infância de 27 de maio de 1911, que deu início à organização de um sistema judicial de proteção às crianças e jovens.
} 
peito da infância, sua concepção e garantia por direitos com consequente vida plena e digna. A Lei de Proteção à Infância de 1911 previu, em seu artigo $1 .^{\circ}$, no título 'Objeto desta lei', o seguinte:

Com os fins de prevenir não só os males sociais que podem produzir a perversão ou o crime entre os menores de ambos os sexos de menos de dezasseis anos completos, ou comprometer a sua vida ou saúde; mas tambêm de curar os efeitos dêsses males, serão criadas as seguintes instituições: Tutoria da Infância; Federação Nacional dos Amigos e Defensores das Crianças. (POIARES, 2010, p. 1).

Segundo Goldschmied; Jackson (2006, p. 13 apud TADEU, 2014), “[...] uma sociedade pode ser julgada pela sua atitude em relação as suas crianças pequenas, não somente no que se diz sobre elas, mas também em como essa atitude é expressada no que lhes é oferecido ao longo de seu crescimento". A lei portuguesa de proteção à infância questionava as condições de carências e privações em que viviam, no geral, as crianças menos favorecidas, em várias dimensões: socioeconômicas, higiênicas, habitacionais e culturais (CANDEIAS; HENRIQUES, 2012). Privações estas que geravam a exposição ao risco social e psíquico. O objetivo macro da lei era reduzir as condições de exclusão e pobreza que imperavam em Portugal naquele período ${ }^{4}$.

O risco e/ou perigo social é uma categoria destacada neste estudo, visto que os marcos legais de defesa pelos direitos da criança aconteceram principalmente a fim de reduzir essa condição. O risco “[...] tem-se revelado um conceito central das sociedades contemporâneas e tem ganhado relevância nos debates públicos e académicos (CRUZ, 2013, p.17), sendo aqui considerado como toda condição de violação de direitos fundamentais que expõem a criança à vulnerabilidade, à marginalização e a condições sociais e educativas indignas e/ou degra-

\footnotetext{
${ }^{4}$ A visão pioneira desta lei de 1911 foi, lamentavelmente, interrompida por um período de quase meio século de ditadura, iniciado em 1926, ao qual a Revolução de 25 de Abril de 1974 pôs termo, abrindo caminho à democracia e à consagração de direitos sociais, económicos e políticos.
} 
dantes. Anica e Raposo-Freire $(2017)^{5}$ consideram que risco significa perigo potencial para a criança, no que se refere à exclusão e aos impactos gerados pelo perigo social iminente, e implica até resultados de avaliação psicológica, consequente das condições precárias no modo de vida, tais como maus tratos, trabalho infantil, abandono, extrema pobreza, exposição a situações que geram insegurança, afetam a saúde física e mental, a educação e o desenvolvimento pleno.

Segundo Candeias; Henriques (2012), a Lei de 1911, de Proteção à Infância, é por isso defensora da redução do risco social, e isto fez com que Portugal se colocasse à frente, no contexto europeu, na garantia de direitos infantis, inicialmente diferenciando-a do adulto, bem como distinguindo o Direito Penal do Direito de Menores. Com essa lei, foi

[...] instituída a primeira Tutoria de Infância, que mais tarde veio dar origem aos atuais Tribunais de Família e Menores e instituídas a Federação Nacional dos Amigos e Defensores das Crianças e os Refúgios. Se em 1911 e 1912, respetivamente, são instituídas as Tutorias em Lisboa e no Porto, o resto do país teve de aguardar pela lei de 1925, que regulamentou a expansão do sistema, concluída apenas no Estado Novo. A lei de Proteção à Infância apenas foi objeto de reforma aquando da publicação da Organização Tutelar de Menores (OTM), em 1962. (CANDEIAS; HENRIQUES, 2012, p.1)

Note-se que Portugal sai à frente até mesmo da Declaração de Genebra, que só ocorre em 1924, a qual menciona os direitos da Cri-

\footnotetext{
${ }^{5}$ Esclarecem que os conceitos de 'criança em risco' e 'criança em perigo' são distintos, porém, complementares. A criança em perigo implicaria a presença de condições como: o abandono, maus tratos físicos, psíquicos e/ou sexuais, falta de afeição, obrigação a trabalhos inadequados e excessivos para a sua idade, exposição a fatos que levam ao desequilíbrio emocional e afetam a segurança, saúde, educação e desenvolvimento. Já o conceito de risco significa perigo potencial para a criança, no que se refere à exclusão e aos impactos gerados pelo perigo social iminente, e implica resultados de avaliação psicológica. Nesse sentido, ambos são aqui importantes de serem destacados.
} 
ança, que deveria ser cuidada, alimentada e reeducada, tendo que ter prioridade no atendimento e no socorro, em caso de perigo. Essa declaração somente foi recomendada pelas Nações Unidas no ano de 1946, e a partir daí cria-se o Fundo de Emergência das Nações Unidas para as Crianças (UNICEF), nome substituído em 1950 para Fundo das Nações Unidas para a Infância (CARDOSO et al, 2017).

É no século XX do pós-guerra, que a criança do contexto ocidental-europeu é concebida como sujeito de direitos, conforme defende Cardoso et al (2017, p.14) “[...]. É no século XX do pós-guerra que emerge a noção da "criança sujeito" de direitos. O grande aumento da taxa de natalidade (designado como baby boom), a diminuição das taxas de mortalidade infantil associadas à melhoria das condições de saúde e de vida, em geral, da população criaram condições para uma reinvenção social da infância.

Em 1948, a Declaração Universal dos Direitos do Homem será o primeiro instrumento internacional que clarifica direitos, incluindo a criança. São direitos cívicos, políticos, sociais e culturais. Em seu artigo 25, a infância é destacada.

Toda a pessoa tem direito a um nível de vida suficiente para lhe assegurar e à sua família a saúde e o bem-estar, principalmente quanto à alimentação, ao vestuário, ao alojamento, à assistência médica e ainda quanto aos serviços sociais necessários, e tem direito à segurança no desemprego, na doença, na invalidez, na viuvez, na velhice ou noutros casos de perda de meios de subsistência por circunstâncias independentes da sua vontade.

A maternidade e a infância têm direito a ajuda e a assistência especiais. Todas as crianças, nascidas dentro ou fora do matrimónio, gozam da mesma protecção social.

No que tange à Educação, o artigo 26 destaca que toda pessoa tem direito à educação, que deve ser gratuita pelo menos no nível fundamental, e os pais possuem a prioridade do direito de escolha do gênero de educação para proporcionar aos seus filhos. Essa lei, enfim, incorpora a criança até então invisibilizada como pessoa de direitos. 
Após a Lei de Proteção à Infância, a nova concepção de infância do pós-guerra e as Declarações de Genebra e dos Direitos do Homem (Humanos), Portugal vai encontrar mais tarde respaldo para a defesa da criança como sujeito de direitos plenos. A Declaração Universal dos Direitos da Criança, de 1959 (também chamada de Declaração de Genebra, dada as suas conexões), será mais um desses marcos que contribuirá para o novo 'olhar' acerca da infância, em Portugal. A Declaração dos Direitos da Criança foi promulgada pelo Conselho da União Internacional de Proteção à Infância (Save the Children Internacional) e estabelece princípios orientadores aos membros da Sociedade das Nações.

Em 1976, a Constituição da República Portuguesa, em seu artigo 69, de título 'Infância', refere-se explicitamente ao direito de proteção das crianças, com uma preocupação com as mais vulneráveis e vivendo em situação de risco, em especial os órfãos e abandonados.

As crianças têm direito à protecção da sociedade e do Estado, com vista ao seu desenvolvimento integral. 2. As crianças, particularmente os órfãos e os abandonados, têm direito a especial protecção da sociedade e do Estado, contra todas as formas de discriminação e de opressão e contra o exercício abusivo de autoridade na família e nas demais instituições.

Em 1989, o país respalda-se também na Convenção sobre os Direitos da Criança, que foi ratificada por Portugal em setembro de 1990, através do Decreto do Presidente da República n.o 49/90 (TADEU, 2014, p. 161). A Convenção tinha como principal defesa o 'interesse superior da criança' e enunciava os direitos que deviam lhe ser conferidos para a sua proteção integral contra

[...] as formas de discriminação, abuso, exploração, injustiça ou conflito, mas também o direito à participação em todos os as suntos que lhe dizem respeito e à educação, cujos objetivos são definidos no artigo $29^{\circ}$ como "promover o desenvolvimento da personalidade da criança, dos seus dons e aptidões mentais e 
físicos na medida das suas potencialidades (alínea a).” A dimensão da participação é de grande importância pois confere às crianças um estatuto ativo, evidencia-as como agentes criativos que contribuem para a produção e transformação das sociedades adultas (CARDOSO, 2017, p.14).

A Convenção está assentada em quatro pilares: a não discriminação, o interesse superior da criança, a sobrevivência e o desenvolvimento e a opinião da criança. Ela se organiza em cinquenta e quatro artigos, distribuídos em quatro categorias (UNICEF, 2019): os direitos à sobrevivência, os direitos relativos ao desenvolvimento, que inclui o da educação, os direitos à proteção e os direitos de participação. Em seu artigo $1^{\circ}$, apresenta a definição de criança: "Nos termos da presente Convenção, criança é todo o ser humano menor de 18 anos, salvo se, nos termos da lei que lhe for aplicável, atingir a maioridade mais cedo". Enfim, a nação portuguesa inicia entre os anos de 1911 e 1989 a formulação de uma nova noção de criança (criança como sujeito de direitos), considerando a síntese dos marcos na figura abaixo:

Figura 2 Proteção da Infância - Marcos iniciais

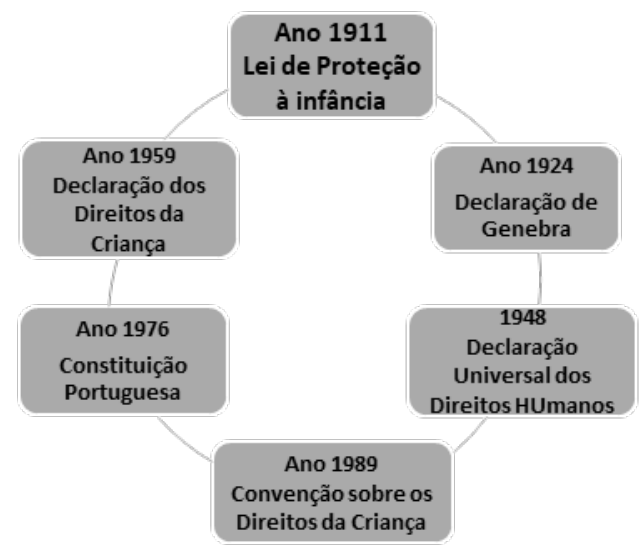

Fonte: autoria própria

É necessário avançar a análise, destacando, agora, as décadas de 1980 e 90 do século passado, como importantes períodos para a prote- 
ção de crianças. A Lei Tutelar Educativa ${ }^{6}$ (n.166/99), por exemplo, revisa a política perante a conduta de crianças/jovens delituosos, aplicando medidas educativas (HERVET, 2016) para aqueles entre 12 e 16 anos; conduta esta enquadrada antes no sistema penal, e este último segue sendo aplicado a jovens maiores de 16 anos. Já a Lei de Proteção de Crianças e Jovens em Perigo, também aprovada em 1999, Lei n. ${ }^{\circ}$ 147/99, partilha do valor internacional de proteção, que se dá também, e principalmente, pelo Estado e Sociedade portuguesa em conjunto. Esta lei

[...] coloca à cabeça dos princípios orientadores da intervenção o superior interesse da criança. Este instituto prevalece sobre qualquer outro princípio e deverá nortear qualquer intervenção que, em função do caso concreto, num determinado período histórico e cultural, atenderá prioritariamente aos interesses e direitos da criança, "sem prejuízo da consideração que for devida a outros interesses legítimos no âmbito da pluralidade dos interesses presentes no caso concreto" (cf. alínea a) (CRUZ, 2013, p. 10).

Reafirma ainda que os direitos das crianças e dos jovens devem pautar-se no respeito pela intimidade, pelo direito à imagem e privacidade. Sugere a prevalência da família, ainda que não única responsável, na promoção da integração da criança na vida familiar e social, dentre outros princípios.

As décadas de 1980 e 90 se destacam também porque ocorreu a ratificação da Convenção sobre os Direitos da Criança de 1989, como instrumento internacional, como já citado. E em sentido mais local, Portugal adota a Convenção Europeia sobre o Exercício dos Direitos da Criança, em 1996, que possuía um caráter mais processual, com medidas que deveriam fazer valer os direitos infantis (ALBUQUERQUE, 2001), atendendo especialmente ao artigo $4^{\circ} \mathrm{da}$ Convenção dos Direitos da Criança, segundo o qual os Estados-Partes, europeus, teriam de tomar as medidas legislativas, administrativas e outras fundamentais para a realização dos direitos infantis.

\footnotetext{
${ }^{6}$ Vide DIÁRIO DA REPÚBLICA (Portugal) — I SÉRIE-A No 215 - 14-9-1999
} 
É no final do século XX e início do XXI, com a ascensão dos direitos humanos, a Declaração Universal dos Direitos Humanos, a Declaração dos Direitos da Criança e a Convenção sobre os Direitos da Criança, que o Brasil passa a formular a elaboração de marcos que dão visibilidade aos direitos das crianças, compreendidos como especiais (MARCÍlIO, 1998). Neste sentido, o Brasil, em comparação a Portugal, destacou-se porque não se limitou apenas a ratificar a Convenção sobre os Direitos da Criança ${ }^{7}$, mas avançou, sistematizando um ordenamento jurídico específico para as crianças e os adolescentes brasileiros, lei mundialmente reconhecida, considerada modelo a ser seguido, o Estatuto da Criança e do Adolescente(ECA), Lei n 8.069, de 13 de julho de $1990^{8}$; conhecida também como paradigma da proteção integral, fruto de ampla luta social que contou com a atuação de várias en tidades como Pastoral do Menor e Movimento Nacional de Meninos e Meninas de Rua, via Fórum Nacional dos Direitos da Criança e dos Adolescentes. Esta lei substitui o antigo Código de Menores (Lei 6697/79) que, segundo Santos (2017, p. 226), “[...] foi a reformulação do conhecido Código Mello Mattos, de 12 de outubro de 1927, Decreto n 17.943, ou paradigma da Situação Irregular do Menor", que tinha como um dos maiores fundamentos o binômio assistencialismo-vigilância.

O antigo 'código de menores' conceituava a criança como menor ou infância menorizada. Esta que, como retrata a citação de Luzy acima, é a abandonada ou em situação irregular! Não se olhava para a criança como um todo, muito menos preocupa-se com a sua proteção e garantia de direitos plenos. A preocupação era a de vigiar e manter a 'teórica' sobrevivência às crianças consideradas 'inadaptadas sociais'. O código de menores preocupase com o conflito social instalado desde o início do século XX, e

\footnotetext{
${ }^{7}$ Portugal ainda hoje utiliza a Convenção como marco na definição de políticas de garantia de direitos da criança portuguesa. Não sistematizou uma lei específica local, diferente do Brasil, que formulou o Estatuto da Criança e do Adolescente.

${ }^{8}$ Infelizmente nota-se que esta lei ainda não foi implantada amplamente. O que ocorre no contexto cultural e social é a violação dos direitos das crianças, em especial das mais vulneráveis.
} 
não com a prevenção, educação, garantia de direitos e reintegração social das crianças!(SANTOS, 2017, p.227)

O ECA, no entanto, edifica uma outra concepção de infância, aquela que é sujeito de direitos e pessoa que deve ter garantido a cidadania plena, com destaque para toda e qualquer criança, conforme in dica o seu artigo $3^{\circ}$ :

A criança e o adolescente gozam de todos os direitos fundamentais inerentes à pessoa humana, sem prejuízo da proteção integral de que trata esta Lei, assegurando-se-lhes, por lei ou por outros meios, todas as oportunidades e facilidades, a fim de lhes facultar o desenvolvimento físico, mental, moral, espiritual e social, em condições de liberdade e de dignidade.

Parágrafo único. Os direitos enunciados nesta Lei aplicam-se a todas as crianças e adolescentes, sem discriminação de nascimento, situação familiar, idade, sexo, raça, etnia ou cor, religião ou crença, deficiência, condição pessoal de desenvolvimento e aprendizagem, condição econômica, ambiente social, região e local de moradia ou outra condição que diferencie as pessoas, as famílias ou a comunidade em que vivem (BRASIL, 1990).

Visão, aliás, que a Constituição Federal Brasileira de 1988 ajudou a construir, pois, segundo Didonet et al (2011), dá destaque para a criação desse 'novo paradigma' de amplos direitos infantis, considerando o direito à Educação Infantil.

Em 2016, validando, alterando e complementando o ECA, é assinada a Lei n. 13.257, intitulada Marco Legal da Primeira Infância, que dispõe sobre as políticas públicas para as crianças de 0 a 6 anos de idade, defendendo-as como prioridade absoluta. Em seu artigo $1^{\circ}$, considera os "[...] princípios e diretrizes para a formulação e a implementação de políticas públicas [...]”, dando atenção à importância dos primeiros anos de vida no desenvolvimento da criança, em articulação com os princípios e as diretrizes do ECA. 


\section{A Educação da Primeira Infância em Portugal e no Brasil}

No que se refere ao direito da criança à Educação de qualidade, ambas as nações evidenciam, em especial a partir das décadas de 1980 e 1990, a urgência de defender e fazer valer esse direito, em especial a Educação de natureza pública destinada a todas as crianças.

Em Portugal, um marco legal fundamental é constituído pela Lei de Bases do Sistema Educativo (LBSE), no 46/86, segundo a qual a educação pré-escolar é complementar e/ou supletiva da ação educativa da família, e a sua frequência é facultativa, no reconhecimento de que à família cabe um papel no processo educativo no nível etário a que se destina - crianças com idade compreendida entre os três anos e a idade de ingresso no Ensino Básico (6 anos). A Educação Pré-escolar é parte integrante do sistema educativo, tendo-lhe sido conferida pela Lei um papel complementar e de cooperação com a família; no entanto, a par do seu caráter facultativo, é universal para crianças a partir dos 4 anos de idade (Lei n. ${ }^{\circ}$ 65/ 2015, de 3 de julho).

Após cerca de uma década da publicação da LBSE, a Lei-Quadro da Educação Pré-escolar, regulamentada pelo Decreto-Lei ${ }^{\circ}$ 5/97, de 10 de fevereiro, vem erigir um novo marco no avanço da educação da primeira infância, na ótica do direito a uma educação de qualidade voltada às crianças de 3 a 6 anos de idade. A educação da primeira infância é considerada a primeira etapa da Educação Básica, definida como serviço social básico. Essa Lei sistematiza princípios pedagógicos orientadores, e funcionamento das redes e sua direção pedagógica, formação de professores e regime de pessoal, dentre outras definições fundamentais para a garantia de qualidade da educação das crianças pequenas.

No entanto, quer a Lei de Bases do Sistema Educativo, quer a Lei-Quadro da Educação Pré-Escolar incluem apenas a educação préescolar a partir dos 3 anos, não abrangendo a educação dos 0 aos 3 anos. Em Portugal, o modo de organização dos designados serviços de "atendimento à primeira infância" está estagnado há décadas, pois a denominada "educação" das crianças dos 0 aos 3 anos de idade não faz 
parte do "sistema educativo", ou seja, não está sob a alçada do Ministério da Educação, mas do Ministério do Trabalho, Solidariedade e Segurança Social. As "respostas" existentes para as crianças dessa faixa etária consistem em três modalidades: Ama, Creche e Creche Familiar. O sentido das lutas recentes por uma educação de qualidade da primeira infância tem colocado justamente o foco nos primeiros anos de idade.

No que tange à organização curricular, o documento Orientações Curriculares para a Educação Pré-Escolar, publicado em 2016, está baseado nos objetivos globais pedagógicos definidos pela LeiQuadro, a fim de apoiar a gestão do Jardim de Infância (PORTUGAL, 2016).

Figura 3 Organização das Orientações

Curriculares para a Educação Pré-Escolar
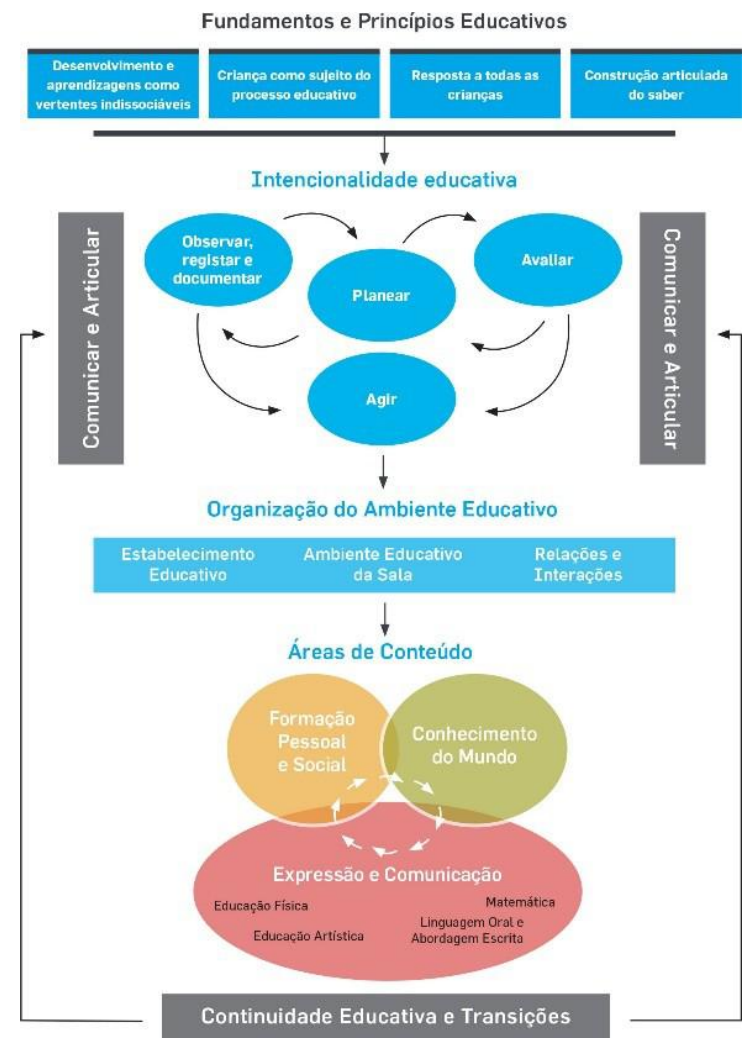

Fonte: Portugal (2016) 
É um documento organizado em três partes: 1. Enquadramento Geral (Fundamentos e princípios da pedagogia para a infância, Intencionalidade educativa - construir e gerir o currículo e Organização do ambiente educativo; 2. Áreas de Conteúdo, que são os fundamentos e princípios da educação de infância (Área de Formação Pessoal e So cial, Área de Expressão e Comunicação, Área do Conhecimento do Mundo); e 3. Continuidade Educativa e Transições, que objetiva considerar o percurso de desenvolvimento e aprendizagem da criança, a fim de criar condições para o sucesso na transição para o $10^{\circ}$ ciclo.

Já a Educação para a Primeira Infância ${ }^{9}$ brasileira, aqui destacaremos a Educação Infantil destinada à criança de 0 a 5 anos de idade (creche 0 a 3 anos) e Pré-escola (4 e 5 anos), está alicerçada tanto na Constituição Federal de 1988 (CF/88), quanto na Lei de Diretrizes e Bases da Educação Nacional (1996), nos Referenciais Curriculares da Educação Infantil (1998), nas Diretrizes Curriculares para a Educação Infantil (2010) e, mais recentemente, na Base Nacional Comum Curricular (2017).

Em 1996, a Lei de Diretrizes e Bases da Educação (n. 9.394) ar ticulou a Educação Infantil ao sistema educacional do país, o que a tornou a primeira etapa da Educação Básica, definida, em seu artigo 29 , como “[...] o desenvolvimento integral da criança de até 6 anos $^{10}$, no seu aspecto físico, psicológico, intelectual e social, completando a ação da família e da comunidade”. (BRASIL, 1996, p. 11) (GUEDES e MARINO, 2014).

No que diz respeito à organização curricular e ao trabalho pedagógico, em 1998 foi sistematizado o Referencial Curricular Nacional para a Educação Infantil (RCNEI). Documento que objetivava o alcance de qualidade para o desenvolvimento integral das crianças de zero a seis. São três volumes: o primeiro contempla a Introdução, que apresenta defesa a respeito das creches e pré-escolas, concepções de educação, de criança e cita os eixos de trabalho que são definidos nos dois

\footnotetext{
${ }^{9}$ No Brasil, a criança de 6 anos integra o Ensino Fundamental desde 2006 (lei n ${ }^{\circ}$ 11.274)

${ }^{10}$ Revisada para 5 anos.
} 
volumes seguintes. O segundo volume apresenta o eixo da experiência 'Formação Pessoal e Social' (identidade e autonomia) e o terceiro volume é relativo ao âmbito de experiência 'Conhecimento de Mundo' (Movimento, Música, Artes Visuais, Linguagem Oral e Escrita, Natureza e Sociedade e Matemática).

Posteriormente, em 2009, a Resolução no 5 fixa as Diretrizes Curriculares Nacionais para a Educação Infantil, com o objetivo de apresentar a organização das propostas pedagógicas desse nível de ensino, agora revisada para crianças de zero a cinco anos de idade (BRASIL, 2009). Com definições de criança, de Educação Infantil, de Currículo e de Proposta Pedagógica, o documento se consolidou como referência na formação de professores, até a mais recente publicação da Base Nacional Curricular (BNCC). O documento destaca, ainda, o processo de avaliação da aprendizagem e a articulação com o ensino fundamental, refletindo acerca do período de transição da criança. Os eixos estruturantes das práticas pedagógicas são as interações e as brincadeiras, valorizando a criança como sujeito histórico, social, de direitos e que interage e brinca e produz cultura. (BRASIL, 2009).

Em 25 de junho de 2014, é sancionado o novo Plano Nacional de Educação (PNE), que estabelece como uma de suas vinte metas (a Meta 1) a universalização da Educação Infantil para as crianças de 4 a 5 anos de idade e a ampliação da oferta da Educação Infantil também em creches ( 0 a 3 ).

Já a Base Nacional Comum Curricular (BNCC), versão aprovada pelo Conselho Nacional de Educação, com a Resolução CNE n. 02/17 (BRASIL, 2017), e em conformidade com a Lei de Diretrizes e Bases da Educação Nacional, define um conjunto de aprendizagens essenciais que deve nortear os currículos, assegurando direitos de aprendizagem e desenvolvimento às crianças, com vistas a criar condições para que as de menor idade aprendam no exercício do papel ativo em situações de interações e brincadeiras. Vale aqui destacar os seis direitos de aprendizagem e desenvolvimento, assim como os respectivos campos de experiência, conforme indica a figura a seguir: 
Figura 4 Mapa da Educação Infantil na BNCC

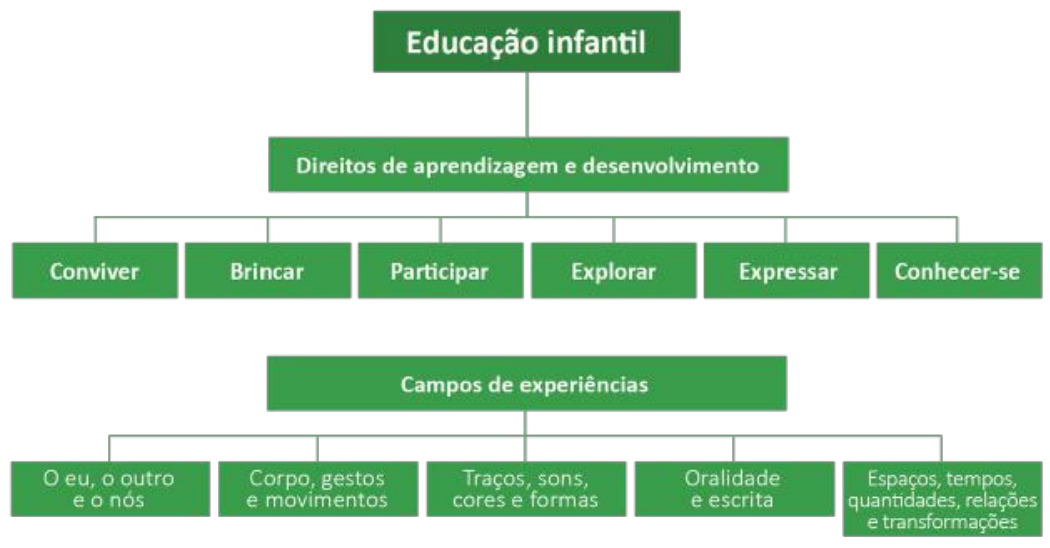

Fonte: Brasil (2017)

Fazendo um paralelo com a organização curricular portuguesa, nota-se que tanto no documento português Orientações Curriculares para a Educação Pré-Escolar, quanto na BNCC para a Educação Infantil no Brasil, o foco no direito ao desenvolvimento e aprendizagens infantis está presente. Além disso, outros pontos de convergência são: o cuidado com o período de transição, ou seja, a saída da criança da educação infantil e sua entrada no $1^{\circ}$ ciclo do Ensino Fundamental, bem como uma visão mais atualizada relativa à Formação Pessoal e Social, com construção da identidade e autonomia infantis e o seu conhecimento de mundo. No entanto, é importante salientar que o documento brasileiro explora e define, com mais clareza, quais são os direitos de aprendizagem e desenvolvimento efetivos que devem ser garantidos às crianças, assim como demarca campos de experiências que devem compor o quadro da formação infantil.

No geral, Portugal e Brasil apresentam as condições legais muito favoráveis à defesa e garantia dos direitos da primeira infância, em especial o direito à educação de qualidade para todas, com destaque, no Brasil, para as mais carentes e da escola pública, que são maioria predominante no país. O principal desafio posto é a permanente validação no cotidiano social e escolar, para que de fato e de direito as crianças de menor idade possam crescer saudáveis e com boa perspectiva 
de desenvolvimento biológico, social, psicológico, afetivo, intelectual, com vistas à atuação competente na sociedade.

Não sendo a História linear, mas composta de lutas, conquistas e retrocessos, é necessária uma crescente vigilância crítica por parte dos pesquisadores/as e de outros atores sociais e políticos, tanto no plano da produção normativo-legal, como da ação concreta de organizações e movimentos sociais. No Brasil, os anos de 1970, ainda sob a intensa repressão política da ditadura militar, foram palco de lutas por direitos protagonizadas por vários movimentos sociais, dentre os quais o Movimento de Luta por Creches (ROSEMBERG, 1984; FINCO; GOBBI; FARIA, 2015). Das conquistas alcançadas, é de salientar a inclusão na Constituição Brasileira da "bandeira da creche como um direito das crianças pequenas ( 0 a 6 anos) à educação em período integral. Pela primeira vez, a criança pequena passou a ser pautada nas políticas públicas específicas que dessem conta da Educação Infantil”. (TELES, 2015, p. 175). Como sublinha esta autora, é hoje necessário "recuperar as diretrizes pedagógicas sob uma perspectiva de gênero, raça/etnia, que haviam sido esboçadas nos anos de 1970 e 1980" (Idem, p. 172).

Nas últimas décadas, em Portugal, o principal foco de discussão e de luta no âmbito da Educação Infantil tem sido a Creche. As designadas "respostas sociais" para crianças entre os 0 e os 3 anos de idade são atualmente de três tipos - Ama, Creche e Creche Familiar - e não fazem parte do sistema educativo. A responsabilidade não é do Ministério da Educação, mas do Ministério do Trabalho, Solidariedade e Segurança Social. Como tal, as reivindicações mais recorrentes, incluindo uma recomendação do Conselho Nacional de Educação, de 2011 (PORTUGAL/CNE, 2011), têm visado garantir uma tutela pedagógica única por parte do Ministério da Educação, tal como já acontece com as crianças de 3-6 anos (FOLQUE; VASCONCELOS, 2019).

O Brasil tem sido palco de intensas tensões e disputas em relação à Educação Infantil, ocorrendo retrocessos políticos paradoxais (SANTOS; MACEDO, 2017). Estas autoras problematizam três para- 
doxos relativamente à situação da educação das "crianças pequeninhas":

[...] o paradoxo entre o direito da criança e o da mulher trabalhadora, que retoma a discussão sobre a responsabilidade da família educar; a insistente dicotomia entre educar e cuidar que reverbera em políticas multissetoriais que podem muitas vezes indicar um retrocesso; a obrigatoriedade da matrícula aos quatro anos de idade (EC 059/2009) que direciona o investimento para a pré-escola e reproduz a já superada cisão da educação infantil (SANTOS; MACEDO, 2017, p.8 ).

Se bem que as diferenças entre países e regiões do mundo sejam incomensuráveis, ao nível dos sistemas educativos, em geral, e da agenda de políticas para a infância, em particular (ROSEMBERG, 2009), não pode ser ignorada uma tendência generalizada de retrocesso e de perda de direitos que vem se observando no âmbito global, com origem, em boa parte, em organismos supranacionais, como a União Europeia, a OCDE, o Banco Mundial, etc. Assiste-se a um discurso global que proclama a importância da educação da primeira infância, porém, não como um valor em si, com finalidades próprias, dentre as quais se inclui, com destaque, o brincar, mas como um valor instrumental, de "capital humano", típico do "edu-capitalismo" (SMITH; TESAR; MYERS, 2016), que está governando a educação, desde a primeira infância, ainda que com maior ou menor intensidade consoante os países.

Em sentido contrário, Ferreira (2015) argumenta que algumas tendências das reformas educacionais contemporâneas, que impõem, por exemplo, a curricularização da Educação de Infância, representam um claro retrocesso, na medida em que acentuam mecanismos tecnocráticos e meritocráticos em detrimento das dimensões democráticas da educação. Enquanto os espaços e os tempos de brincar vão minguando, aumenta o pendor acadêmico do currículo, assim como aumentam as formas de socialização e aprendizagem com caráter instrumental e preparatório (aprender a ler, escrever e contar; estar sentado, 
quieto, calado, "bem-comportado"), quer dos níveis de ensino subsequentes, quer de uma força de trabalho obediente e disciplinada. A esta tendência, é necessário contrapor uma maior valorização das vivências democráticas, conviviais e lúdicas das crianças pequenas, tanto nos contextos de educação coletiva como em outros mundos da sua vida cotidiana.

\section{Palavras Finais}

No que concerne à defesa e à garantia de uma educação de qualidade para as crianças pequenas e os bebês, têm ocorrido avanços significativos em vários países e regiões do mundo, porém, em simultâneo com a estagnação e mesmo retrocesso em outros. No processo sócio-histórico e político de construção de importantes instrumentos internacionais, sobretudo a partir da segunda metade do século XX, como a Declaração Universal dos Direitos da Criança (1959) e a Convenção sobre os Direitos da Criança (1989), é de registar que a grande ênfase por eles conferida às crianças, de um modo geral, não se tem verificado com a mesma intensidade no que tange à primeira infância.

Ainda que Portugal e Brasil apresentem marcos de significativo valor para a garantia dos direitos infantis, os desafios são muitos e é preciso seguir fortalecendo o debate relativo à ampliação da qualidade da educação da primeira infância, em especial àquelas em risco ou mais carentes; além disso, validá-los como ação cotidiana no contexto da vida social mais ampla. Valorizar os marcos legais já reconhecidos historicamente pela comunidade educativa e pela sociedade sem, contudo, deixar de olhar para o futuro, a fim de seguir reconhecendo que o investimento na educação de qualidade para a primeira infância é viés de desenvolvimento e crescimento das nações.

Os esforços pela manutenção e validação desses marcos devem ser conjuntos. Estado, família, educadores, organizações e movimentos sociais de defesa da infância devem seguir participando das decisões políticas que afetam a vida das crianças, sem deixar de escutá-las e incluí-las, para a efetiva garantia de direitos. Note-se que as lutas 
por uma educação de qualidade na primeira infância são hoje particularmente necessárias, atendendo, por um lado, ao tempo de perda de direitos em que vivemos e, por outro, às fortes tendências de curricularização da Educação Infantil, sendo ainda mais preocupante o fato de essas tendências abrangerem já, também, as crianças bem pequenas.

Aos avanços registados historicamente na qualidade da educação para/na primeira infância não é alheia à influência exercida por um conjunto de tratados, declarações, convenções e outros tipos de documentos internacionais em torno dos Direitos - direitos civis, políticos e direitos sociais, econômicos e culturais - conquistados ao longo do tempo, especialmente no que toca aos direitos da criança e do/a adolescente. No entanto, é de salientar a enorme contribuição de organizações e movimentos sociais diversos para que essa educação de qualidade tenha sido assumida - e continue sendo assumida - como uma política pública e um direito fundamental das crianças. Para a concretização dos direitos juridicamente consagrados em práticas sociais e educativas contextualizadas, as reivindicações e lutas protagonizadas, especialmente quando atuaram/atuam de um modo articulado: movimentos de trabalhadoras(es), estudantes, intelectuais pesquisadoras(es), sindicalistas, feministas, entre outros. Face a estagnações, derivas e retrocessos vários, esses movimentos e lutas não podem esmorecer.

\section{Referências}

ALBUQUERQUE, Catarina. Os direitos da criança: As Nações Unidas, a convenção e o comité. Gabinete de Documentação e Direito Comparado. 2011.

ANICA, Aurízia; FREIRE-RAPOSO, Sofia. Crianças em Risco. Um olhar multifacetado. Algarve: Edição Soroptimist Internacional Clube de Tavira/Universidade do Algarve, 2017. 
BRASIL Marco Legal da Primeira Infância. 2016. Disponível em <http://www.planalto.gov.br/ccivil 03/ Ato2015-2018/2016/Lei/ L13257.htm $>$ Acesso em: 8 maio 2018.

. Ministério da Educação. Secretaria de Educação Básica. Diretrizes curriculares nacionais para a educação infantil / Secretaria de Educação Básica. - Brasília: MEC, SEB, 2010.

. Constituição da República Federativa do Brasil: texto constitucional promulgado em 5 de outubro de 1988, com as alterações determinadas pelas Emendas Constitucionais de Revisão nos 1 a 6/94, pelas Emendas Constitucionais nos 1/92 a 91/2016 e pelo Decreto Legislativo no 186/2008. - Brasília: Senado Federal, Coordenação de Edições Técnicas, 2016. Disponível em: <https://www2.senado.leg.br/ bdsf/bitstream/handle/id/518231/CF88 Livro EC91 2016.pdf $>$ Acesso em: 13 jul. 2019.

. Estatuto da Criança e do Adolescente. Lei 8.069, de 13 de julho de 1990. Brasília. Disponível em: <http://www.planalto.gov.br/ccivil 03/leis/18069.htm $>$ Acesso em: 15 abr. 2017.

Lei de Diretrizes e Bases da Educação Nacional (LDB). Lei 9.394, de 20 de dezembro de 1996. Brasília. Disponível em: < $\underline{\text { http:// }}$ www.planalto.gov.br/ccivil 03/leis/19394.htm > Acesso em: 24 abr. 2018.

Lei de Diretrizes e Bases da Educação Nacional. Lei n. ${ }^{\circ}$ 9.394, 20 de dezembro de 1996. Disponível em: <http://www.planalto.gov.br/ ccivil 03/LEIS/L9394.htm> Acesso em: 15 ago. 2019.

- Ministério da Educação. Conselho Nacional de Educação. Resolução $\mathrm{CNE} / \mathrm{CP} \mathrm{n}^{\circ}$ 2, de 22 de dezembro de 2017. Base Nacional Comum Curricular - BNCC. Disponível em: $<$ http://basenacionalcomum.mec.gov.br/images/BNCC EI EF 110518 versaofinal site.pdf> Acesso em: 7 jun. 2019.

Ministério da Educação. Secretaria de Educação Básica. Referencial curricular nacional para a educação infantil / Ministério da 
Educação e do Desporto, Secretaria de Educação Fundamental. -Brasília: MEC/SEF, 1998.

CANDEIAS, Marisa; HENRIQUES, Helder. 1911/2011: Um século de Proteção de Crianças e Jovens. Trabalho apresentado no III Seminário de I\&DT, organizado pelo C3i - Centro Interdisciplinar de Investigação e Inovação do Instituto Politécnico de Portalegre, realizado nos dias 6 e 7 de Dezembro de 2012. Disponível em: < https://comum.rcaap.pt/bitstream/10400.26/4156/1/Marisa\%20Candeias Helder \%20Henriques.pdf.> Acesso em: 7 fev. 2020.

CARDOSO, Ana; SILVA; Ana Paula; LANSDOWN, Gerison. Formação em Direitos das Crianças - A Convenção em Prática Referencial de Formação. CESIS - Centro de Estudos para a Intervenção Social. Lisboa, fevereiro de 2017.

CRUZ, Maria Inês Poeiras Simões da Conceição Ivo. O Perigo e a Tipologia do Abuso na Lei de Proteç̧ão de Crianças e Jovens em Perigo. Dissertação de Mestrado, Instituto Universitário de Lisboa, 2013. Disponível em < https://repositorio.iscte-iul.pt/bitstream/10071/7500/1/ Tese Final.pdf. $>$ Acesso em: 08 fev. 2020.

DIDONET, Vital et al. Educação infantil no Brasil: primeira etapa da educação básica. Brasília: UNESCO, Ministério da Educação/Secretaria de Educação Básica, Fundação Orsa, 2011.

FERREIRA, Fernando Ilídio. Contributos de John Dewey e Ivan Illich para pensar a atualidade de um projeto de animação infantil e comunitária. In: FERREIRA, Fernando Ilídio; ANJOS, Cleriston Izidro dos (Orgs.). Educação de Infância: formação, identidades e desenvolvimento profissional. Santo Tirso/Maceió: De Facto Editores/Edufal, 2015. p. 131-153

FINCO, Daniela; GOBBI, Marcia Aparecida; FARIA, Ana Lúcia Goulart de. Apresentação - Um olhar feminista para os direitos das crianças. In: FINCO, Daniela; GOBBI, Marcia Aparecida; FARIA, Ana Lúcia Goulart de (orgs.). Creche e Feminismo. Desafios atuais para uma educação Descolonizadora. Campinas, SP: Edições Leitura Crítica; As- 
sociação de Leitura do Brasil; São Paulo: Fundação Carlos Chagas, 2015.

FOLQUE, Maria Assunção; VASCONCELOS, Teresa. Que educação para as crianças dos 0 aos 3 anos? Estado da Educação 2018. Lisboa: Conselho Nacional de Educação, p.278-289, 2019.

GUEDES, Patricia Mota; MARINO, Eduardo (Coord.). Educação Infantil em Debate: a experiência de Portugal e a realidade brasileira. São Paulo: Fundação Itaú Social: Fundação Maria Cecília Souto Vidigal, 2014.

HERVET, Andreia Filipa Martinho. A (Nova) Lei Tutelar Educativa: Análise Crítica de Magistrados. Tese de Mestrado em Política Social. Universidade de Lisboa: Lisboa, 2016.

MARCÍLIO, Maria Luiza. A lenta construção dos direitos da criança brasileira. São Paulo: Revista da USP, 1998.

MISKOLCI; Richard; PELÚCIO, Larissa. Discursos fora da ordem. Sexualidades, saberes e direitos. São Paulo: Annablume, 2012.

NAUDEAU, Sophie et al. Como investir na Primeira Infância. um guia para a discussão de políticas públicas e a preparação de projetos de desenvolvimento da Primeira Infância. São Paulo: Singular, 2011.

NERI, Marcelo. Educação da Primeira Infância. São Paulo: FGV, 2005. PIOVESAN, Flavia. Direitos sociais, econômicos e culturais e direitos civis e políticos. In: Sur. Revista Internacional de Direitos Humanos, v.1 n.1 São Paulo, 2004, <https://doi.org/10.1590/S1806$\underline{64452004000100003>}$

POIARES, Carlos. Edição Comemorativa da Lei de Proteção à Infância, 27 de Maio de 1911. Instituto da Segurança Social, I.P. Ano 2010. Disponível em <http://www.seg-social.pt/documents/10152/13588/ lei_proteccao infancia/955222e6-dcab-4fe1-b0f5-82d0c9bc40e9> Acesso em: 7 fev. 2020.

PORTUGAL. Orientações Curriculares para a Educação Pré-Escolar. Ministério da Educação. Isabel Lopes da Silva (coord.). 2016. Disponí- 
vel em $<$ https://www.dge.mec.pt/ocepe/sites/default/files/Orientacoes Curriculares.pdf $>$ Acesso em: 5 fev. 2020.

. Lei de Bases do Sistema Educativo. Diário da República Eletrônico. Disponível em < https://dre.pt/web/guest/legislacao-consolidada/-/lc/70328402/201908311800/70486656/diploma/indice?consolidacaoTag=Educa $\%$ C3\%A7\%C3\%A3o+e+Ensino $>$ Acesso em: 10 fev. 2020.

. Lei de Proteção à Infância, de 27 de maio de 1911, In Diário do Governo, de 27 de Maio de 1911: pp. 1316-1331. Disponível em $<$ http://www.seg-social.pt/documents/10152/13588/lei proteccao infancia/955222e6-dcab-4fe1-b0f5-82d0c9bc40e9> Acesso em: 5 fev. 2020

. Lei de Proteção de Crianças e Jovens em Perigo. Aprovada pela Lei n. ${ }^{\circ} 147 / 991 .^{\text {a }}$ série - N. ${ }^{\circ} 175$ - Portugal: 8 de setembro de 2015.

PORTUGAL/CNE. Recomendação no 3/2011. A educação dos 0 aos 3 anos. Lisboa: Conselho Nacional de Educação (Relatora Teresa Vasconcelos), 2011. Disponível em: <http://www.cnedu.pt/content/edicoes/estado da educacao/

Estado da Educacao2018 web 26nov2019.pdf> Acesso em $11 \mathrm{fev}$. 2020.

ROSEMBERG, Fúlvia. A criança pequena na agenda de políticas para a infância: representações e tensões. In: PALACIOS, Jesús;

CASTÑEDA, Elsa. (Orgs.). A primeira infância (0 a 6 anos) e seu futuro. Madri: Fundação Santillana, 2009. Disponível em: $<\underline{\text { http://www.di- }}$ versidadeducainfantil.org.br>. Acesso em: 26 fev. 2014.

. O movimento de mulheres e a abertura política no Brasil - $\mathrm{O}$ caso da creche. Caderno de Pesquisas. São Paulo, p.73-79, Nov. de 1984. Disponível em: <http://publicacoes.fcc.org.br/ojs/index.php/cp/ article/view/1462/1457>. Acesso em: 22 fev. 2020.

SANTOS, Ana Katia Alves dos. A emergência da criança como sujeito de direitos na Educação Infantil. In: Revista Zero-a-seis, v. 19, n. 36, 
p. 223-234, jul-dez 2017, Disponível em < https://periodicos.ufsc.br/ index.php/zeroseis/article/view/1980-4512.2017v19n36p223 > Acesso em: 22 fev. 2020.

SANTOS, Ana Katia Alves dos; QUEIROZ, Adriana Franco. Infância e o paradigma da proteção integral: reflexões sobre direitos e situação de trabalho. Revista entreideias, Salvador, v. 8, n. 2, p. 27-50, maio/ago. 2019. Disponível em: $<$ https://portalseer.ufba.br/index.php/entreideias/article/view/27605/19324> Acesso em: 20 jan. 2020.

SANTOS, Solange; Elina, MACEDO. Direito da Criança pequenininha a creche: disputas e retrocessos na Educação Infantil. 2017. Revista Nuances: estudos sobre Educação, Presidente Prudente-SP, v. 28, n. 3, p. 8-22, Set/Dez, 2017. Disponível em <http://revista.fct.unesp.br/index.php/Nuances/article/view/5269/PDF>. Acesso em: 15 fev. 2020.

SMITH, Kylie; TESAR, Marek; MYERS, Casey Y. Edu-capitalism and the governing of early childhood education and care in Australia, New Zealand and the United States. Global Studies of Childhood, v. 6, n 1, p. 123-135. 2016. <https://doi.org/10.1177/2043610615625165> Acesso em: 15 fev. 2020.

TADEU, Bárbara. A legislação Portuguesa para a pequena infância: uma visão sociológica sobre a infância. Revista Interações, n. 30, p. 159-175, 2014. Disponível em <file://C:/Users/al201/Downloads/ 4029-Texto\%20do\%20Trabalho-10524-1-10-20140620\%20(7).pdf> Acesso em: 10 jan. 2020.

TELES, Maria Amélia de Almeida. Creche em tempos de perdas de direitos! In: TELES, Maria Amélia de Almeida; SANTIAGO, Flávio; FARIA, Ana Lúcia Goulart de (Orgs.). Por que a creche é uma luta das mulheres? São Carlos: Pedro \& João Editores, 2018, p. 163-179.

UNICEF. Convenção sobre os Direitos da Criança e protocolos facultativos. Edição Comitê Português para a UNICEF. 2019. Disponível em: <https://www.unicef.pt/media/2766/unicef convenc-a-o dos direitos da crianca.pdf $>$ Acesso em: 12 fev. 2020. 